\title{
Clinicopathological, Immunohistochemical, and PMS2 Gene Expression Profiling of Patients with Sporadic Colorectal Cancer
}

\author{
Maryam Mousavi, PhD'; ${ }^{1}$ Mohammad Taghi Goodarzi, PhD²; Seyed Mehrdad Kassaee, PhD'; Ali Jafari Heidarloo, MD ${ }^{3}$; Mojtaba Fathi, PhD ${ }^{4 *}$ \\ 'Department of Biology, Faculty of Basic Science, Islamic Azad University, Hamedan Branch, Hamedan, Iran \\ ${ }^{2}$ Department of Biochemistry, Islamic Azad University, Shahrood Branch, Shahrood, Iran \\ ${ }^{3}$ Gastroenterology Subdivision of Internal Medicine Department, Imam Khomeini Hospital, Urmia University of Medical Sciences, Urmia, Iran \\ ${ }^{4}$ Department of Biochemistry, School of Medicine, Zanjan University of Medical Sciences, Zanjan, Iran
}

\begin{abstract}
Background: The DNA mismatch repair (MMR) system is one of the molecular pathways involved in colorectal cancer (CRC) carcinogenesis that consists of several genes, including MLH1 (MutL homolog 1), MSH6 (MutS homolog 6), MSH2 (MutS homolog 2), and MSH3 (MutS homolog 3). The protein encoded by PMS2 (post-meiotic segregation 2) is also essential for MMR. Here, we address the correlation between immunohistochemical and transcriptional expression of PMS2 with the tumor grade and clinical stage of non-hereditary/sporadic CRC disease.

Methods: This study retrospectively analyzed 67 colorectal resections performed for 38 male and 29 female patients. Random biopsies were taken by a gastroenterologist from patients referring to three hospitals in the cities of Zanjan, Urmia and Qazvin (Iran) during 2017-2019. All specimens were examined and classified for localization of tumor, pathological stage and grade. The PMS2 protein expression was studied immunohistochemically and analysis of mRNA expression was performed in the same tissue sections.

Results: Immunohistochemistry and quantitative real-time polymerase chain reaction (PCR) analysis showed a decrease in PMS2 expression compared with paracancerous tissue $(P<0.001)$, which correlated with tumor stage. In addition, reduced PMS2 expression was correlated with the tumor differentiation grade, underlining a connection between downregulation of PMS2 and progression of CRC. Comparing the PMS2 mRNA levels in different groups showed the following results: $0.92 \pm 0.18$ in patients with Stage I CRC tumor, $0.86 \pm 0.38$ in Stage II, $0.50 \pm 0.29$ in Stage III, and $0.47 \pm 0.23$ in Stage IV.

Conclusion: These findings suggest that PMS2 may provide a potential reliable biomarker for CRC classification by combined immunohistochemical and mRNA analysis.

Keywords: Colorectal cancer, Immunohistochemistry, Mismatch repair, Neoplasm staging, PMS2 gene

Cite this article as: Mousavi M, Goodarzi MT, Kassaee SM, Jafari Heidarloo A, Fathi M. Clinicopathological, immunohistochemical, and PMS2 gene expression profiling of patients with sporadic colorectal cancer. Arch Iran Med. 2021;24(2):86-93. doi: 10.34172/ aim.2021.13.
\end{abstract}

Received: March 29, 2020, Accepted: October 20, 2020, ePublished: February 1, 2021

\section{Introduction}

Colorectal cancer (CRC) is one of the most common cancers and the second leading cause of cancer-related deaths in the world. ${ }^{1}$ Annually, over 1.23 million new cases are diagnosed with CRC (OMIM \#114500) and it is estimated that about 600000 deaths from CRC occur worldwide. ${ }^{2}$ The disease is found to occur equally in both genders, second to breast cancer among females and third to lung and prostate for males, globally. ${ }^{3}$

In contrast to the familial type which is caused by germ-line mutations, sporadic CRC develops by the accumulation of a series of somatic mutations in tumor suppressor genes and oncogenes. Hereditary CRC includes hereditary nonpolyposis colon cancer (HNPCC), also known as Lynch syndrome (OMIM \#120435) and familial adenomatous polyposis (FAP) (OMIM \#175100). The familial/hereditary type accounts for $10 \%-20 \%$ of CRC cases while $80 \%-90 \%$ of CRC cancers show evidence of sporadic clustering of the disease. ${ }^{4}$

Several acquired genetic mutations are commonly involved in the pathological processes linked to sporadic CRC risk in human populations; among which $A P C$ (Adenomatous polyposis coli) (OMIM \#611731), P53 (OMIM\#191170), DCC (deleted in colorectal carcinoma) (OMIM \#120470), MCC (mutated in CRCs) (OMIM \#159350), and SMAD4 (SMA- and MAD-related protein 4) (OMIM \#600993) are tumor suppressors and some others such as Beta-catenin, CTNNB1 (encoding for $\mathrm{K}-\mathrm{Ras} \beta$ Catenin, c-myc proteins) (OMIM \#116806) are oncogenes. ${ }^{5}$ DNA mismatch repair (MMR), an important genome caretaker system, has been extensively studied and deficient DNA MMR seems to be important in cancer 
development since the major MMR genes are found to be mutated in many tumors. Given the increasing importance of the involvement of MMR abnormalities in sustaining cancer development, further consideration deserves to be given as to whether dysfunction of the DNA MMR genes is associated with CRC. This is of great importance in genetic research, particularly of nonhereditary cases which represent the most common CRC type. Characterizing hereditary versus sporadic CRC cases and the underlying molecular signatures may also provide indications regarding prognosis and risk of disease development. Initial studies in the field have shown evidence of defective MMR in CRC patients regardless of sporadic or familial origin. Further characterization suggests that components of the MMR machinery could serve as target genes for detection and genotyping of nonhereditary-sporadic CRC cancers. ${ }^{6}$

The DNA mismatch-repair system includes MSH2 (MutS homolog 2), MSH3/6 (MutS homolog 3/6), MLH1 (MutL homolog 1) and PMS2 (post-meiotic segregation 2). ${ }^{7}$ Genetic as well as epigenetic changes in the MMR genes which induce MMR system failure have been increasingly recognized in the carcinogenesis process. The most commonly mutated MMR genes in human cancers are MLH1 (OMIM: \#120436), MSH2 (OMIM \#609309) and MSH6 (OMIM \#600678).8,9 PMS2 (OMIM \#600259) also referred to as HNPCC4, PMS2CL, PMSL2, MLH4, PMS1 homolog 2, and MMR system component, is an essential component in eukaryotic DNA MMR ${ }^{10}$; however, mutations in this MMR gene are rare in the etiology of patients with a family history of CRC. ${ }^{11}$ PMS2 is one of five MMR genes embedded within a complex genomic locus on chromosome 7 (band p22.1). There are a number of PMS2 pseudogenes on the same chromosome, the presence of which complicate the identification and mutational analysis of PMS2 gene. ${ }^{12}$ Recent advances in mutation detection technologies have allowed clinical testing for PMS2 mutations; however, there are still some challenges about whether any of the mutations in PMS2 gene are missed or miscalled as a result of the presence of pseudogenes.

Mismatch repair component PMS2 is one of several mammalian homologs of the Escherichia coli MutL DNA MMR gene, an enzyme that, in humans, is encoded by the PMS2 gene comprised of 15 exons. ${ }^{13}$ As one of a complex of proteins in the DNA MMR system, PMS2 endonuclease activity, when in complex with MLH1, is capable of incising a defective DNA strand and thus along with MSH2, MSH6 and EXO1, corrects small errors involving mispaired nucleotides to ensure the fidelity of the newly-replicated DNA strand. ${ }^{14}$

Recent studies in humans have linked MMR proteins with dual functions in DNA damage repair and signaling pathways inducing apoptosis in the face of excess DNA damage. Mechanistically, one of the models that can be considered for MMR signaling pathways is the hydrolysisindependent sliding clamp (SC) model. The SC model is alike to $\mathrm{G}$ protein molecular switch systems. Functional complexes of the MMR proteins, unlike bacterial MutS and MutL which function as homodimers, the eukaryotic MutS homolog (MSH) and MutL homolog (MLH) proteins function as heterodimers. ${ }^{15}$ The "hydrolysisindependent SC" model suggests that the MMR proteins are signaling molecules. These MMR proteins function as "direct sensors" that contribute to signaling pathways that may either provoke DNA repair or apoptosis. ${ }^{16}$

Germ-line mutations in the PMS2 gene leading to loss of MMR function appear to underlie the development of a variety of hereditary malignancies such as colon cancer, ovarian, gastric, pancreatic, endometrial and prostate cancer. ${ }^{17-20}$ Insights into the genetic basis of colon cancer families have revealed that $10 \%-15 \%$ of CRCs are due to defects in MMR represent non-hereditary sporadic form of CRCs for which screening is generally recommended. ${ }^{21}$ Although sporadic colorectal carcinogenesis is not a rare pathological entity, little is known about its cytogenetic and pathological features necessary to identify prognostic biomarkers for early diagnosis. The adverse consequences of the delay between onset and diagnosis may be a more advanced stage of disease without clinical evidence of metastatic disease. ${ }^{22,23}$ Identification of factors associated with the clinicopathologic discrepancy could be used for assessment of disease severity. The aim of this study is to investigate the correlation of PMS2 expression and parameters of age, sex, primary tumor location and differentiation grade as well as cancer stage that would enable an earlier diagnosis to be made. In this population-based study of patients with sporadic CRC, we examined PMS2 expression by immunohistochemistry and quantitative gene expression assay with real-time polymerase chain reaction (PCR). To our knowledge, this is the first study combining immunohistochemical and real-time quantitative PCR techniques designed to elucidate the importance of PMS2 expression pattern in tumor tissue as a prognostic factor in patients with sporadic CRC.

\section{Materials and Methods}

Sample Collection

The sample size was calculated using the appropriate statistical formula and the results of the study by Karahan et al. ${ }^{29}$ According to this mentioned study, in order to compare the rate of PMS2 gene expression in patients suffering from CRC cancer in different stages with the healthy control group, and considering a clinical difference rate of $50 \%$ in gene expression between higher stage colon tumors and normal tissues, the standard sample size using Cochrane formula was calculated 19 in each group with $95 \%$ validity and $90 \%$ power of the test based on the results from normal group $(9.7 \%)$ and stage III CRC 
cancer $(76.3 \%)$.

$n=\frac{(1.96+1.28)^{2}[0.097(1-0.097)]+[0.763(1-0.763)]}{\left(\frac{0.763}{2}\right)^{2}}=19$

Sixty-seven colonoscopy tissue samples from CRC patients were collected from patients referring to three hospitals in Iran: Vali-e-Asr hospital, Imam Khomeini hospital and Velayat hospital in the cities of Zanjan, Urmia and Qazvin, respectively, from 2017 to 2019. The patients were selected randomly and a tumor tissue sample and a normal sample located $12 \mathrm{~cm}$ apart from the tumor site were collected from each patient.

After pathological confirmation by a hospital pathologist, the specimens were nominated for experimental studies. Written informed consent was taken from all participants.

RNA Extraction and Reverse Transcription

All biopsy tissue specimens were transferred to $1.5 \mathrm{~mL}$ micro-tubes containing RNAlater solution. For the storage of biopsies, the tubes were first kept at $4^{\circ} \mathrm{C}$ up to about 12-24 hours followed by long-term storage at $-70^{\circ} \mathrm{C}$. Total RNA extraction was carried out with RNX plus Sinaclon Bioscience, Karaj, Iran (Cat. \#RN7713C) according to the manufacturer's instructions, and the concentration of isolated RNA was then determined using Thermo Nanodrop. To allow the isolation of RNA free from genomic DNA contamination, the RNA extracts were treated by DNase using the EN0521 (Fermentas, Germany) isolating total RNA free from genomic DNA.

After removal of genomic DNA, the preparations of RNA were subjected to reverse transcription to synthesize the complementary DNA (cDNA) using the Thermo Scientific kit RevertAid First Strand cDNA Synthesis Kit (Thermo Scientific, USA. Cat. \#k1622).

\section{Real-Time Polymerase Chain Reaction}

We used quantitative the real-time PCR technique to quantify the amount of PMS2 gene expression in normal and tumoral tissue samples. Gene expression was detected using SYBR Premix Ex TaqII (Takara Bio Inc., Japan). Primer pairs were designed for exons 3 and 4 using the NCBI database. Beta-actin gene was used as the internal control gene for all tissue samples. The primer sequences for PMS2 gene were as follows: forward: 5'-GAAGTTTCAGACAATGGATGTGG-3' and reverse primer: 5'-TAGGTCGCAAACTCTTGAATC3'. For beta-actin: forward primer was 5'-CTTGATGTCACGGACGATT-3', and reverse primer was 5'-CACGGCATTGTCACCAACT-3'.

All the reactions were performed in triplicate. The PCR products were then subjected to electrophoresis on $1.5 \%$ agarose gel for further analysis.

Immunohistochemical Analysis

In this study, immunohistochemistry (IHC) was used to assay PMS2 protein content. Immunohistochemical staining by monoclonal antibody was used to perform IHC using a rabbit tissue monoclonal antibody prepared from Aragen Company namely (Monoclonal Rabbit Anti-Human-Post-Meiotic Segmentation 2-clone EP51) (Tashkhis Baft Aragene-Dako, Tehran, Iran) that specifically detects target proteins. This antibody binds only to its own specific protein in the tissue section. Then, during the production of color by the enzyme attached to the secondary antibody, the protein expression can be investigated through a substrate capable of producing color at sites of target protein. ${ }^{24}$

After collecting paraffin blocks from patients' specimens, tissue sections were placed on charged slides and then immunohistochemistry was performed according to the manufacturer's protocol.

Finally, the slides were scanned using an optical camera microscope and the photos were captured at a magnification of $40 \mathrm{x}$.

The analysis of protein expression by semi-quantitative method using the scoring system produced repeatable results. PMS2 expression was reported semi-quantitatively for 45 tumor samples with the Remmele score system.

\section{Statistical Analysis}

Statistical analysis was performed using SPSS software version 16 and data plots were generated using the GraphPad Prism 7 (GraphPad Software Inc., La Jolla, CA, USA). First, the data were checked for normal distribution using Kolmogorov-Smirnov test and Normal Q-Q Plot. Levene test for homogeneity of variance was conducted. An Ordinal Logistic Regression was used to assess associations of tumor stage with PMS2 protein expression intensity in CRC tissues. For normal data, analysis of variance (ANOVA) was used to compare the mean of the variables studied in different stages of the disease; to compare the mean of variables between normal and cancerous tissues, the independent $t$ test was used. For variables that were not normal, we used the MannWhitney $U$ test and for nominal variables, chi-square tests for large expected cell counts, otherwise replaced by Fisher exact test. To investigate the relationship between gene expression and other variables, for normal and nonnormal distributions of quantitative variables, the Pearson and Spearman rank correlation coefficient tests were performed, respectively. Nonparametric Kruskal-Wallis H test was used to compare the intensity of PMS2 expression in four stages of the disease. $P$ values less than 0.05 were considered as statistically significant in hypotheses.

\section{Results}

Tumor and adjacent normal tissues as control were obtained from 67 patients [38 (57\%) males and 29 (43\%) females] with sporadic CRC. The mean age of the patients was $61 \pm 12$ years (ranged 36 to 76 years). The median size of resected specimens was $0.2 \times 0.2 \times 0.2 \mathrm{~cm}$. The surgical 
specimens were divided into four groups based on the stage of the disease. These experimental groups included Stage I $=9(13.4 \%)$, Stage II = 23 (34.3\%), Stage III $=17(25.4 \%)$, and Stage IV = 18 (26.9\%) tumors and their respective control groups. We further provided full information on the tumor growth, in terms of the tumor location (in colon, cecal colon, transverse colon, sigmoid, rectum, rectosigmoid, cecum and ascending colon) and tumor differentiation grade which characterized the phenotypic properties of these cells into three subtypes: well-differentiated, moderately differentiated, and poorly differentiated. A summary of the clinicopathological parameters of the patients is shown in Table 1. Based on ANOVA results, the mean age of the patients in the four stages was not significantly different $(P=0.108)$.

The quantitative method of real-time PCR was used to investigate the molecular changes in PMS2 mRNA expression in normal and colorectal tumor tissues. The results showed that the PMS2 mRNA level in the tumor tissues was significantly decreased, indicating the association of PMS2 with malignant phenotype of CRC cells.

Tukey's post hoc test, comparing the expression of PMS2

Table 1. Number of Cases According to Clinicopathological Parameters

\begin{tabular}{|c|c|c|}
\hline Variables & Number of Cases & $\%$ \\
\hline \multicolumn{3}{|l|}{ Sex } \\
\hline Male & 38 & 56.7 \\
\hline Female & 29 & 43.3 \\
\hline \multicolumn{3}{|l|}{ Age $(y)$} \\
\hline$<61$ & 27 & 40.3 \\
\hline$>61$ & 40 & 59.7 \\
\hline \multicolumn{3}{|c|}{ Location primary tumor } \\
\hline Colon & 7 & 10.3 \\
\hline Cecal colon & 5 & 7.5 \\
\hline Transverse colon & 4 & 6.0 \\
\hline Sigmoid & 17 & 25.4 \\
\hline Rectum & 18 & 26.9 \\
\hline Recto sigmoid & 7 & 10.4 \\
\hline Cecum & 3 & 4.5 \\
\hline Ascending colon & 6 & 9.0 \\
\hline \multicolumn{3}{|l|}{ Differentiation } \\
\hline Well & 24 & 35.8 \\
\hline Moderate & 24 & 35.6 \\
\hline Poor & 11 & 16.7 \\
\hline Undifferentiated & 8 & 11.9 \\
\hline \multicolumn{3}{|c|}{ Gene expression level in tumor } \\
\hline Absent & 32 & 45 \\
\hline Present & 35 & 00 \\
\hline \multicolumn{3}{|l|}{ Stage } \\
\hline I & 9 & 13.4 \\
\hline II & 23 & 34.3 \\
\hline III & 17 & 25.4 \\
\hline IV & 18 & 26.9 \\
\hline
\end{tabular}

gene expression at the mRNA level between the normal and tumor cells from different stages of growth, showed significantly lower PMS2 expression in all tumor stages (in Stage I; $P=0.039$, in Stage II; $P=0.015$, in Stage III; $P<0.0001$ and in Stage IV; $P<0.0001$, Figure 1). When comparing between the groups, the highest PMS2 gene expression was observed in Stage II tumors, and a statistically significant difference compared to Stages III and IV $(P=0.045$ and $P=0.026$, respectively) was noted.

Paraffin blocks were cut by microtome (CUT 2040-Company Germanic) to 4 microns in thickness. After IHC staining with anti-PMS2 antibodies and optical microscopy, the following results were obtained. The DAB sedimentation analysis, which is brown on the tissue, was evaluated for at least five fields for each tumor and the intensity of tumor cell staining was scored. The intensity of PMS2 protein expression was calculated with semi-quantitative scores. The number of positive staining cells was counted per square millimeter of tissue. The average percentage of PMS2-positive stained tumor cells was determined in terms of expression and was divided into four groups: PMS2-negative expression (group 1), expression less than 1\% (group 2), 1\%-50\% (group 3), and 51\%-100\% (group 4). The intensity of PMS2-staining is reported as negative expression, +1 , $+2,+3$, indicative of weak, moderate and strong degree of expression, respectively. Also, we used the Remmele Score system, which shows the quantitative amount for protein expressions which is the product of the percentage of stained cells in the stain intensity (which could value from 0 to 9). Immunohistochemical fields of tissues with weak PMS2 protein expression were associated with colon cancer. The results in comparison with various stages show a reduction in the average percentage of expression of PMS2 protein in the tumor tissue, especially after stage II.

Figure 2 illustrates immunohistochemical staining for PMS2 protein in normal and tumoral tissues. Normal tissue samples showed high PMS2 protein expression levels and

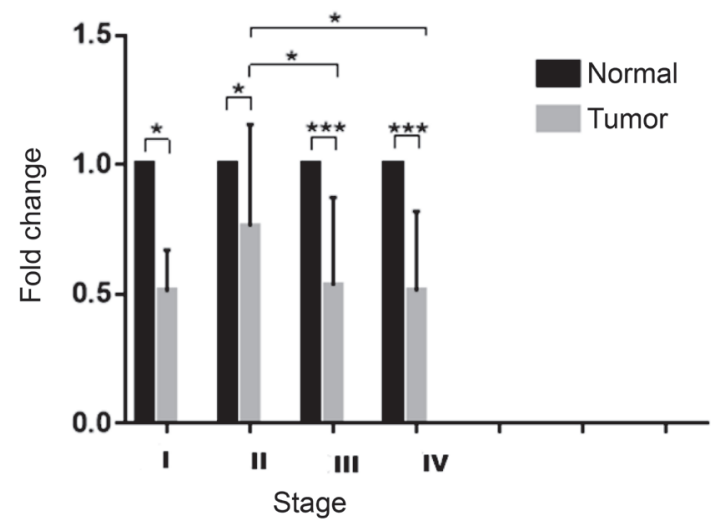

Figure 1. Relative Expression Level of PMS2 mRNA in Different Stages of Colorectal Cancer Compared to Their Control Group. ${ }^{*} P<0.05$; ${ }^{*} P<0.01$; $* * * P<0.0001$. 

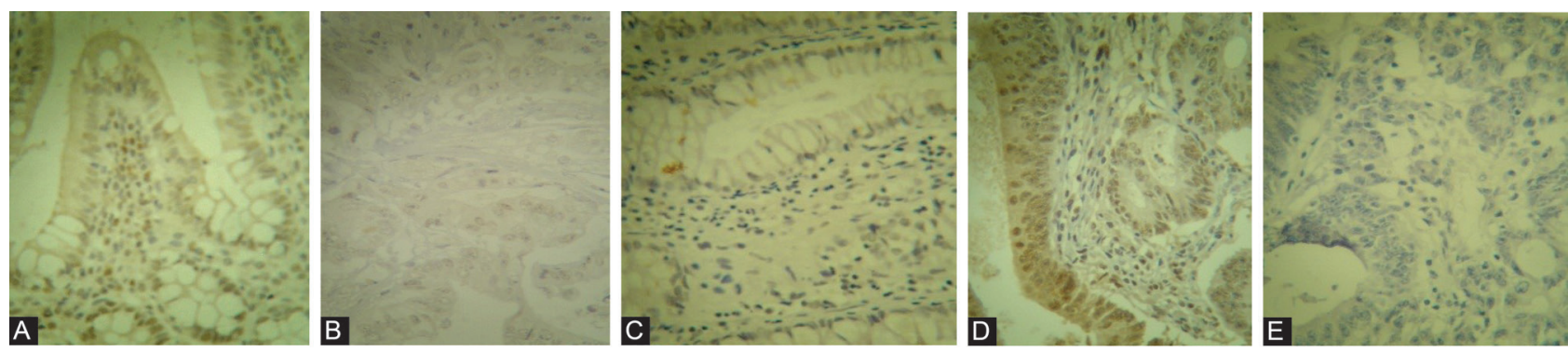

Figure 2. Immunohistochemical Staining of Colorectal Tumors for PMS2 Marker (PMS-2, x400) Visualized by DAB (brown). (A) Immunohistochemistry expression of PMS2 protein showed that normal tissue samples were positive for PMS2 protein expression (positive control). (B) Tumoral tissue with low intensity PMS2 protein expression (+) represent tumors in higher stages. (C) Tumoral tissue showing moderate intensity for PMS2 protein expression (++) which is associated with early stage cancer. (D) Tumoral tissue showing high intensity for PMS2 protein expression (+++), and (E) absence of PMS2 expression (Negative control).

tumoral tissues showed decreased or loss of PMS2 protein expression as follows: low-intensity protein expression (+, weak positive) regarded as well-differentiated, moderatedintensity protein expression (++, positive) regarded as moderately differentiated, and high-intensity protein expression (+++, strong positive) was regarded as poorly differentiated tumors. The percentage of PMS2 protein expression by immunohistochemical staining is shown in Table 2. In PMS2 staining of experimental tissue samples, 32 out of 71 tumor cases $(45.1 \%)$ were negative $(P=0.01)$.

Using Fisher's Exact test, we compared the intensity of PMS2 expression in different stages of the disease with their control group (normal tissue). Confounding adjustment was not performed due to small sample size. Tissue samples from four disease stages had lower expression of PMS2 than the control groups (Table 3). The intensity of PMS2 expression in four stages of the disease was significantly different $(P=0.01)$. ANOVA showed a significant difference in the percentage protein expression in different stages; with increasing the stage of CRC cancer, the intensity and percentage of PMS2 protein expression decreased significantly $(P=0.01)$.

As shown in Table 4, the odds ratio of PMS2 positive expression between the experimental groups and the

Table 2. Percent of the Cases According to Staining of the Immunohistochemical Marker

\begin{tabular}{llll}
\hline PMS2 expression (\%) & $51-100$ & $1-50$ & $1<$ \\
\hline Cases $(\%)$ & 29.6 & 23 & 1.4 \\
\hline
\end{tabular}

control group was significant with values of $0.1,0.191$, and 0.034 for stage IV, stage III, and stage II tumors, respectively, (all values $<1$ ). PMS2 protein expression was measured semi-quantitatively (Remmele score) using immunohistochemistry. The PMS2 median Remmele score was found to be $-5.46 \pm 0.95(P=0.001),-3.01 \pm$ $1.05(P=0.044)$, and $-3.99 \pm 1.13(P=0.007)$ for stage II, stage III, and stage IV tumor tissues, respectively, compared to the normal group (Table 5).

In Figure 3, the Box Plot compares the intensity of expression and the percentage of protein expression between the four stages and the control group. In both plots, the median and percentiles of $25^{\text {th }}$ and $75^{\text {th }}$ in the control group were higher than those of different tumor stages, and stages II and IV had the lowest percentile of protein expression and intensity. Based on the nonparametric Kruskal-Wallis $\mathrm{H}$ Test, the distribution of protein expression percentage $(P=0.003)$ and its intensity $(P<0.001)$ were different in various stages. Figure 3 shows a significant relationship between the intensity of PMS2 protein expression and different stages of the disease $(P<0.001)$. Figure 3 demonstrates a significant relationship between the percentage of protein expression and different stages of the disease. Four stages have a lower percentage of protein expression than the normal group $(P=0.003)$. finally, Figure 3 shows the intensity of PMS2 staining in the Remmele Score system, which was significantly higher in the normal tissues than tumoral tissues $(P<0.001)$.

Table 3. Amount of Protein Expression in Normal Tissue Compared to Tumor Tissue in Four Different Stages of the Diseases

\begin{tabular}{|c|c|c|c|c|c|c|}
\hline \multirow{2}{*}{ Variable } & & & \multicolumn{4}{|c|}{ Intensity } \\
\hline & & & - & $1+$ & $2+$ & $3+$ \\
\hline \multirow{5}{*}{ Groups } & Normal & No. (\%) & $6(20.7)$ & $0(0.0)$ & $5(17.2)$ & $18(62.1)$ \\
\hline & Stage I & No. (\%) & $2(50.0)$ & $0(0.0)$ & $2(50.0)$ & $0(0.0)$ \\
\hline & Stage II & No. $(\%)$ & $13(81.3)$ & $0(0.0)$ & $3(18.8)$ & $0(0.0)$ \\
\hline & Stage III & No. (\%) & $5(41.7)$ & $1(8.3)$ & $4(33.3)$ & $2(16.7)$ \\
\hline & Stage IV & No. (\%) & $6(60.0)$ & $0(0.0)$ & $3(30.0)$ & $1(10.0)$ \\
\hline Total & & No. $(\%)$ & $32(45.1)$ & $1(1.4)$ & $13(23.9)$ & $21(29.6)$ \\
\hline
\end{tabular}

$P=0.01$. 
Table 4. Parameter Estimates. Association Between the Intensity of Protein Expression and Different Stages of the Disease

\begin{tabular}{|c|c|c|c|c|}
\hline \multirow{2}{*}{ Parameters } & \multirow{2}{*}{$P$ value } & \multirow{2}{*}{ Odds Ratio } & \multicolumn{2}{|c|}{ 95\% Wald Confidence Interval for OR } \\
\hline & & & Lower & Upper \\
\hline Stage IV & 0.002 & 0.100 & 0.022 & 0.443 \\
\hline Stage III & 0.013 & 0.191 & 0.052 & 0.708 \\
\hline Stage II & $<0.001$ & 0.034 & 0.007 & 0.157 \\
\hline Stage I & 0.032 & 0.117 & 0.016 & 0.835 \\
\hline Normal (Reference group) & - & 1 & - & - \\
\hline
\end{tabular}

Dependent Variable: Intensity.

Model: (Threshold), Groups.

Table 5. Mean Difference of Percentage of Protein Expression and Remmele Score between Stages of the Disease

\begin{tabular}{|c|c|c|c|c|c|c|}
\hline \multirow{2}{*}{ Dependent Variable } & \multirow{2}{*}{ (I) Groups } & \multirow{2}{*}{ (J) Groups } & \multirow{2}{*}{ Mean Difference (I-J) } & \multirow{2}{*}{$P$ Value } & \multicolumn{2}{|c|}{ 95\% Confidence Interval } \\
\hline & & & & & Lower Bound & Upper Bound \\
\hline \multirow{10}{*}{$\begin{array}{l}\text { Percentage of protein } \\
\text { expression }\end{array}$} & Stage I & Normal & -25.905 & 0.628 & -77.72 & 25.91 \\
\hline & \multirow{2}{*}{ Stage II } & Normal & -47.030 & $<0.001$ & -77.28 & -16.78 \\
\hline & & Stage I & -21.125 & 0.811 & -75.43 & 33.18 \\
\hline & \multirow{3}{*}{ Stage III } & Normal & -13.155 & 0.803 & -46.50 & 20.19 \\
\hline & & Stage I & 12.750 & 0.968 & -43.34 & 68.84 \\
\hline & & Stage II & 33.875 & 0.090 & -3.22 & 70.97 \\
\hline & \multirow{4}{*}{ Stage IV } & Normal & -27.655 & 0.201 & -63.28 & 7.97 \\
\hline & & Stage I & -1.750 & 1.000 & -59.22 & 55.72 \\
\hline & & Stage II & 19.375 & 0.638 & -19.79 & 58.54 \\
\hline & & Stage III & -14.500 & 0.864 & -56.10 & 27.10 \\
\hline \multirow{10}{*}{ Remmele score } & Stage I & Normal & -3.84483 & 0.143 & -8.4384 & 0.7488 \\
\hline & \multirow{2}{*}{ Stage II } & Normal & -5.46983 & $<0.001$ & -8.1519 & -2.7877 \\
\hline & & Stage I & -1.62500 & 0.877 & -6.4395 & 3.1895 \\
\hline & \multirow{3}{*}{ Stage III } & Normal & -3.01149 & 0.044 & -5.9677 & -.0553 \\
\hline & & Stage I & .83333 & 0.990 & -4.1391 & 5.8057 \\
\hline & & Stage II & 2.45833 & 0.234 & -.8306 & 5.7473 \\
\hline & \multirow{4}{*}{ Stage IV } & Normal & -3.94483 & 0.007 & -7.1032 & -.7865 \\
\hline & & Stage I & -.10000 & 1.000 & -5.1952 & 4.9952 \\
\hline & & Stage II & 1.52500 & 0.733 & -1.9468 & 4.9968 \\
\hline & & Stage III & -.93333 & 0.954 & -4.6210 & 2.7543 \\
\hline
\end{tabular}

\section{Discussion}

It is well established that early detection and accurate disease progression prediction benefit from integrating molecular analysis with clinical data. An outstanding example is FAP - an inherited condition where a genotype-phenotype correlation for the $A P C$ gene exists. ${ }^{25}$ As mentioned earlier, technical difficulties in analyzing the PMS2 gene mutations due to pseudogenes is clearly consistent with a significant underreporting of PMS2 mutations that indicates poor understanding of the CRC genetic risk. ${ }^{26}$ Yet the immunohistochemical analysis of tumor samples carries significant clinical implications. ${ }^{27}$ Using this method, we found that the immunohistochemical staining pattern of PMS2 in the colorectal tumors contrasts with the adjacent normal tissues. Importantly, PMS2 was differentially expressed in normal, premalignant, and malignant colorectal tissues supporting the idea that PMS2 expression was in some way associated with tumor initiation and progression. By itself, PMS2 may have significant impact on early CRC detection in sporadic cases and thus, will have implications for future diagnostic and treatment measures. CRC is one of the most appropriate cancer types for prevention and early diagnosis. ${ }^{28}$ Since sporadic CRC under the age of 40 is often very rare, ${ }^{29}$ in our study, the mean of age in the subjects was $61 \pm 12$ years. Multicentric sporadic CRC samples were collected and the expression of PMS 2 was measured at both protein and mRNA levels. In addition, most tumors were located in the rectum and sigmoid colon, and the majority had a moderately to well differentiated grade of cancer. The results showed that both PMS2 protein and gene expression were significantly lower in the tumor tissue than in the area considered as normal. Furthermore, in malignant tissues, the expression rate of PMS2 decreased gradually from benign colorectal tumors (stage I) to malignant CRC (stage IV), indicating that decreased PMS2 expression is associated with stage, grade, and histologic features of the tumor.

Our study is a population-based examination with 

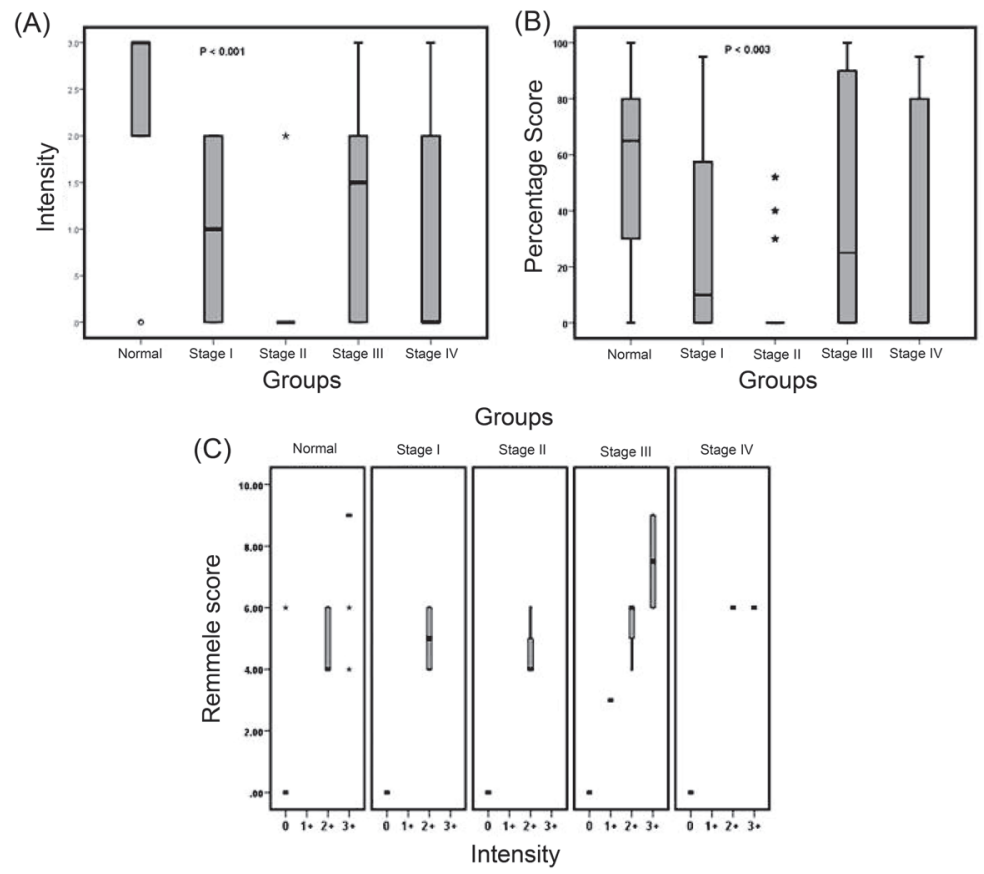

Figure 3. Association between the Intensity of PMS2 Protein Expression (A), Percentage of PMS2 Expression (B), and Remmele Score (C) with Different Stages of Colorectal Tumors (Outlier *).

a small number of participants which yielded similar results to some previous reports. For example, Ioana et al studied the expression level of MMR genes in normal, polyp and malignant tissues in sporadic CRC, using real-time quantitative reveres-transcription $\mathrm{PCR}^{6}$ and showed that the MMR expression level in normal tissues was significantly higher than tumor tissues. Our findings characterized the PMS2 expression patterns with molecular and immunohistochemical confirmation.

Also, Senter et al took an important step by exploring the clinical characteristics of Lynch syndrome patients who had loss of PMS2 expression by immunohistochemistry and demonstrated that in a large series of PMS2 mutation carriers, the incidence of CRC was 5.2-folds higher compared with the general population. ${ }^{30}$ Notably, PMS2 expression results obtained by immunohistochemistry were concordant with its mutational analysis. Based on the available data, it seems reasonable to conclude that PMS2 mutations appear to contribute significantly to CRCs and clinical screening recommendations for PMS2 mutation carriers may potentially improve the disease outcome in sporadic CRC patients. In the present study, quantitative analysis in $45 \%$ of the studied tumors showed decreased expression of PMS2 gene expression. Our results showed that there was a correlation between decreased PMS2 gene expression and the incidence of CRC cancer. However, one of the main limitations of our research was the small number of the specimens evaluated. There is a possibility of sparse-data bias in Table 4 due to the wide confidence interval of odds ratio which is a limitation of this study because of small sample size in some groups. Moreover, it is recommended that for future studies, both the interacting partners of MLH1 and PMS2 be evaluated to explore whether the reduction in PMS2 is independent of changes in its heterodimeric partner, MLH1, which may reveal more details on CRC cancer pathogenesis and surveillance guidelines. We suggest that each of the four major MMR markers including MLH1, MSH2, PMS2, and MSH6 should be investigated which may prove more helpful in predicting the tumor behavior.

In conclusion, low expression of PMS2 gene in mRNA and protein levels was demonstrated in CRC. The mutations occurring in PMS2 gene can result in genome instability. This instability is probable to lead to colon cancer. Failure to correctly repair the DNA damages may also lead to many forms of other cancers.

\section{Authors' Contribution}

MM, MTG, and MF: Study concept and design. MM, and MTG: Drafting of the manuscript. AJH: Sample collection. SMK: Data collection and analysis. MTG and MF: Editing of the manuscript. MTG: Supervision.

\section{Conflict of Interest Disclosures}

Authors had no conflict of interest to declare.

\section{Ethical Statement}

The study was approved by the Ethic Committee of Islamic Azad University, Hamedan, Iran.

\section{Funding}

This study was supported financially by the Islamic Azad University, Hamedan, Iran and was carried out by collaboration with the Zanjan University of Medical Sciences, Zanjan, Iran.

\section{References}

1. Fan J, Shang D, Han B, Song J, Chen H, Yang JM. Adoptive 
cell transfer: Is it a promising immunotherapy for colorectal cancer? Theranostics. 2018;8(20):5784-800. doi: 10.7150/ thno. 29035.

2. Kuipers EJ, Rösch T, Bretthauer M. Colorectal cancer screening-optimizing current strategies and new directions. Nat Rev Clin Oncol. 2013;10(3):130-42. doi: 10.1038/ nrclinonc.2013.12.

3. HimaVyshnavi A, Lakshmi AC, Deepak O, Namboori PK. Evaluation of colorectal cancer (CRC) epidemiology a pharmacogenomic approach. J Young Pharm. 2017;9(1):36-9. doi: $10.5530 /$ jyp.2017.9.7.

4. Yamagishi H, Kuroda H, Imai $\mathrm{Y}$, Hiraishi $\mathrm{H}$. Molecular pathogenesis of sporadic colorectal cancers. Chin J Cancer. 2016;35(1):4. doi: 10.1186/s40880-015-0066-y.

5. Allen JI. Molecular biology of colon polyps and colon cancer. Semin Surg Oncol. 1995;11(6):399-405. doi: 10.1002/ ssu.2980110606.

6. Ioana M, Angelescu C, Burada F, Mixich F, Riza A, Dumitrescu $\mathrm{T}$, et al. MMR gene expression pattern in sporadic colorectal cancer. J Gastrointestin Liver Dis. 2010;19(2):155-9.

7. Umar A, Risinger JI, Hawk ET, Barrett JC. Testing guidelines for hereditary non-polyposis colorectal cancer. Nat Rev Cancer. 2004;4(2):153-8. doi: 10.1038/nrc1278.

8. Hegde M, Blazo M, Chong B, Prior T, Richards C. Assay validation for identification of hereditary nonpolyposis colon cancer-causing mutations in mismatch repair genes $\mathrm{MLH1}$, MSH2, and MSH6. J Mol Diagn. 2005;7(4):525-34. doi: 10.1016/S1525-1578(10)60584-3.

9. Caldés T, Godino J, Sanchez A, Corbacho C, Hoya M, Asenjo $\mathrm{J}$, et al. Immunohistochemistry and microsatellite instability testing for selecting $\mathrm{MLH1}, \mathrm{MSH} 2$ and MSH6 mutation carriers in hereditary non-polyposis colorectal cancer. Oncol Rep. 2004;12(3):621-9. doi: 10.3892/or.12.3.621.

10. Lin Z, Nei M, Ma H. The origins and early evolution of DNA mismatch repair genes-multiple horizontal gene transfers and co-evolution. Nucleic Acids Res. 2007;35(22):7591-603. doi: 10.1093/nar/gkm921.

11. Wang WC, Lee YT, Lai YC. PMS2 gene mutation results in DNA mismatch repair system failure in a case of adult granulosa cell tumor. J Ovarian Res. 2017;10(1):22. doi: 10.1186/s13048017-0317-4.

12. Nicolaides NC, Carter KC, Shell BK, Papadopoulos N, Vogelstein B, Kinzler KW. Genomic organization of the human PMS2 gene family. Genomics. 1995;30(2):195-206. doi: 10.1006/geno.1995.9885.

13. Chen PC, Dudley S, Hagen W, Dizon D, Paxton L, Reichow D, et al. Contributions by MutL homologues Mlh3 and Pms2 to DNA mismatch repair and tumor suppression in the mouse. Cancer Res. 2005;65(19):8662-70. doi: 10.1158/0008-5472. CAN-05-0742.

14. Modrich $\mathrm{P}$, Lahue R. Mismatch repair in replication fidelity, genetic recombination, and cancer biology. Annu Rev Biochem. 1996;65(1):101-33. doi: 10.1146/annurev. bi.65.070196.000533.

15. Lan Z, Sever-Chroneos Z, Strobeck MW, Park CH, Baskaran $\mathrm{R}$, Edelmann $\mathrm{W}$, et al. DNA damage invokes mismatch repairdependent cyclin D1 attenuation and retinoblastoma signaling pathways to inhibit CDK2. J Biol Chem. 2002;277(10):837281. doi: 10.1074/jbc.M108906200.

16. Li Z, Pearlman AH, Hsieh P. DNA mismatch repair and the DNA damage response. DNA Repair. 2016;38:94-101. doi: 10.1016/j.dnarep.2015.11.019.

17. Rosty C, Clendenning M, Walsh MD, Eriksen SV, Southey MC, Winship IM, et al. Germline mutations in PMS2 and MLH1 in individuals with solitary loss of PMS2 expression in colorectal carcinomas from the Colon Cancer Family Registry Cohort. BMJ Open. 2016;6(2):e010293. doi: 10.1136/ bmjopen-2015-010293.

18. Talseth-Palmer BA, McPhillips M, Groombridge C, Spigelman A, Scott RJ. MSH6 and PMS2 mutation positive Australian Lynch syndrome families: novel mutations, cancer risk and age of diagnosis of colorectal cancer. Hered Cancer Clin Pract. 2010;8(1):5. doi: 10.1186/1897-4287-8-5.

19. Grindedal EM, Møller P, Eeles R, Stormorken AT, Bowitz-Lothe IM, Landrø SM, et al. Germ-line mutations in mismatch repair genes associated with prostate cancer. Cancer Epidemiol Prev Biomarkers. 2009;18(9):2460-7. doi: 10.1158/1055-9965. EPI-09-0058.

20. Kobayashi H, Ohno S, Sasaki Y, Matsuura M. Hereditary breast and ovarian cancer susceptibility genes. Oncol Rep. 2013;30(3):1019-29. doi: 10.3892/or.2013.2541.

21. Mundade R, Imperiale TF, Prabhu L, Loehrer PJ, Lu T. Genetic pathways, prevention, and treatment of sporadic colorectal cancer. Oncoscience. 2014;1(6):400. doi: 10.18632/ oncoscience. 59 .

22. Esteva M, Ramos M, Cabeza E, Llobera J, Ruiz A, Pita S, et al. Factors influencing delay in the diagnosis of colorectal cancer: a study protocol. BMC Cancer. 2007;7(1):86. doi: 10.1186/1471-2407-7-86.

23. Rijo Issac N. A Study of the Clinicopathological Profile and Prevalence of CDX2 Biomarker Expression in Primary Adenocarcinoma of Colon in a Tertiary Care Hospital among Indian population. Doctoral dissertation, Christian Medical College, Vellore, 2019.

24. Fan LF, Dong WG, Jiang CQ, Xia D, Liao F, Yu QF. Expression of putative stem cell genes Musashi- 1 and $\beta 1$-integrin in human colorectal adenomas and adenocarcinomas. Int J Colorectal Dis. 2010;25(1):17. doi: 10.1007/s00384-009-0791-2.

25. Aretz S, Stienen D, Friedrichs N, Stemmler S, Uhlhaas S, Rahner $\mathrm{N}$, et al. Somatic APC mosaicism: a frequent cause of familial adenomatous polyposis (FAP). Hum Mutat. 2007;28(10):98592. doi: 10.1002/humu.20549.

26. Ten Broeke SW, Brohet RM, Tops CM, van der Klift HM, Velthuizen ME, Munar IBC, et al. Lynch syndrome caused by germline PMS2 mutations: delineating the cancer risk. J Clin Oncol. 2015;33(4):319-25. doi: 10.1200/JCO.2014.57.8088.

27. Lindor NM, Burgart LJ, Leontovich O, Goldberg R, Cunningham J, Sargent D, et al. Immunohistochemistry versus microsatellite instability testing in phenotyping colorectal tumors. J Clin Oncol. 2002;20(4):1043-8. doi: 10.1200/ JCO.2002.20.4.1043.

28. Jiricny J, Nyström-Lahti M. Mismatch repair defects in cancer. Curr Opin Genet Dev. 2000;10(2):157-61. doi: 10.1016/ S0959-437X(00)00066-6.

29. Karahan B, Argon A, Yıldırım M, Vardar E. Relationship between $\mathrm{MLH}-1, \mathrm{MSH}-2, \mathrm{PMS}-2, \mathrm{MSH}-6$ expression and clinicopathological features in colorectal cancer. Int J Clin Exp Pathol. 2015;8(4):4044-53.

30. Senter L, Clendenning M, Sotamaa K, Hampel H, Green J, Potter JD, et al. The clinical phenotype of Lynch syndrome due to germline PMS2 mutations. Gastroenterology. 2008;135(2):419-28. e411.doi:10.1053/j.gastro.2008.04.026. 